\title{
Removal of hexavalent chromium from aqueous solution by lignocellulosic solid wastes
}

\author{
${ }^{*}$ M. Aliabadi, K. Morshedzadeh and H. Soheyli \\ Department of Chemical Engineering, Islamic Azad University, Birjand Branch, Birjand, Iran \\ Received 11 February 2006; revised 15 May 2006; accepted 2 June 2006; available online 25 June 2006
}

\begin{abstract}
The batch removal of $\mathrm{Cr}(\mathrm{VI})$ from aqueous solution using lignocellulosic solid wastes such as sawdust and pine leaves under different experimental conditions was investigated in this study. The influence of $\mathrm{pH}$, temperature, contact time, initial concentration of $\mathrm{Cr}(\mathrm{VI})$ and particle size on the chromium removal was investigated. Adsorption of $\mathrm{Cr}(\mathrm{VI})$ is highly $\mathrm{pH}$-dependent and the results indicate that the optimum $\mathrm{pH}$ for the removal is 2 . The capacity of chromium adsorption at equilibrium by these natural wastes increased with absorbent concentration. Temperature in the range of $20-60{ }^{\circ} \mathrm{C}$ showed a restricted effect on the adsorption capacity of pine leaves, but had a considerable effect on the adsorption capacity of sawdust. The capacity of chromium adsorption at the equilibrium increased with the decrease in particle sizes. The suitability of adsorbents was tested with Langmuir and Freundlich isotherms and their constants were evaluated. Results indicated that the Freundlich model gave a better fit to the experimental data in comparison with the Langmuir equation. The study showed that lignocellulosic solid wastes such as sawdust and pine leaves can be used as effective adsorbents for removal of $\mathrm{Cr}(\mathrm{VI})$ from wastewater.
\end{abstract}

Key words: Lignocellulosic solid wastes, sawdust, pine leaves, adsorption, hexavalent chromium

\section{INTRODUCTION}

Hexavalent chromium is present in the effluents produced during the electroplating, leather tanning, and cement, mining, dyeing and fertilizer and photography industries and causes severe environmental and public health problems. Hexavalent chromium has been reported to be toxic to animals and humans and it is known to be carcinogenic (Cieslak-Golonka, 1996). Its concentrations in industrial wastewaters range from 0.5 to $270 \mathrm{mg} / \mathrm{l}$ (Patterson, 1985). The tolerance limit for $\mathrm{Cr}$ (VI) for discharge into inland surface waters is $0.1 \mathrm{mg} / \mathrm{L}$ and in potable water is $0.05 \mathrm{mg} / \mathrm{l}$ (EPA, 1990). In order to comply with this limit, it is essential that industries treat their effluents to reduce the $\mathrm{Cr}(\mathrm{VI})$ to acceptable levels. The commonly used procedures for removing metal ions from effluents include chemical precipitation, lime coagulation, ion exchange, reverse osmosis and solvent extraction (Juang and Shiau, 2000; Yan and Viraraghavan, 2001). These techniques apart from being economically expensive have disadvantages like incomplete metal removal, high reagent and energy requirements, and generation of toxic sludge or other waste products that require disposal. Efficient and environment friendly

*Corresponding author, Email: majid.aliabadi@gmail.com Tel.: +0561-2225747; Fax: +0561-2225747 methods are thus needed to be developed to reduce heavy metal content. In this context, considerable attention has been focused in recent years upon the field of sorption by lignocellulosic solid wastes such as straw, coconut husks, exhausted coffee (Dakiky et al., 2002), waste tea (Amir et al., 2005), walnut skin, coconut fibre (Espinola et al., 1999), seeds of Ocimum Basilicum (Melo and Disouza, 2004), defatted rice bran, rice hulls, soybean hulls and cotton seed hulls (Marshall and Champagne, 1995; Teixeria and Zezzi, 2004), wheat bran, pea pod, cotton and mustard seed cakes, (Iqbal et al., 2002; Saeed et al., 2002). The aim for this research is to develop inexpensive and effective chromium ion adsorbents from plentiful sources of natural wastes, such as tree leaves and sawdust to offer these adsorbents as replacements for existing commercial materials. However, to our knowledge, few such studies have been performed previously to use the tree leaves to clean the wastewater.

\section{MATERIALSAND METHODS}

Preparation of Chromium solution

Standard stock solution was prepared from potassium dichromate. For each experimental run, a solution of $\mathrm{Cr}$ metal ion was added to exact amount of deionized water 
in a volumetric flask in order to obtain a known concentration of the metal. $\mathrm{pH}$ of the solution was adjusted using $0.1 \mathrm{~N} \mathrm{HCl}$ or $\mathrm{NaOH}$. Fresh dilutions were used for each study.

\section{Biosorbent materials}

Pine leaves were gathered from twigs into clean plastic bags, washed with deionized water and laid flat on clean table to dry. Dry leaves were grounded, sieved and stored into plastic bag by size, and ready for use.

\section{Adsorption experiment}

Batch adsorber tests were carried out by mechanical agitation (agitation speed: $300 \mathrm{rpm}$ ) at $25^{\circ} \mathrm{C}$, unless stated otherwise. After agitation, all sample solutions were filtered through $0.45 \mu \mathrm{m}$ membrane filter paper and the filtrate was analyzed. The amount of adsorbed $\mathrm{Cr}$ (VI) was calculated by the difference of the initial and residual amount in the solution divided by the weight of the adsorbent used. To check the repeatability of the experimental data, each experiment was conducted thrice.

\section{Chromium detection}

For all experiments, the method of detection is by colorimetric techniques. The chromium is first to be complexed with a solution of 1,5 diphenyl carbazide (DIPC) in acetone, acidified and then, tested in a spectrophotometer set at $540 \mathrm{~nm}$.

\section{RESULTS}

\section{Effect of contact time}

Preliminary experiments showed that the adsorption of chromium ions by sawdust and pine leaves reached equilibrium in less than 15 minutes. Fig. 1 shows the experimental results of adsorption of containing $5 \mathrm{mg} /$ $1 \mathrm{Cr}(\mathrm{VI})$. The experiments were carried out under the conditions of $25^{\circ} \mathrm{C}$, particle size of 20-30 mesh, with 4 $\mathrm{g}$ of adsorbent in $100 \mathrm{~mL}$ of chromium solution with $\mathrm{pH}=5$. All sample solutions were filtered through 0.45 $\mu \mathrm{m}$ membrane filter paper and, the filtrate was analyzed. The experiments showed that the removal rate occurs quickly, seemly reaching equilibrium within the first fifteen minutes of adsorption.

\section{Effect of adsorbent mass}

As illustrated in Fig. 2, capacity of chromium adsorption at equilibrium increases with the quantity of adsorbent either sawdust or pine leaves introduced
(1-10 g/100L); this can be explained by the fact that more the mass increases, more the contact surface offered to the adsorption of chromium becomes important. Beyond $6 \mathrm{~g}$ of pine leaves, this capacity of chromium did not nearly rise and the maximal quantity at the equilibrium of chromium removal by pine leaves was about $0.12 \mathrm{mg} / \mathrm{g}$.

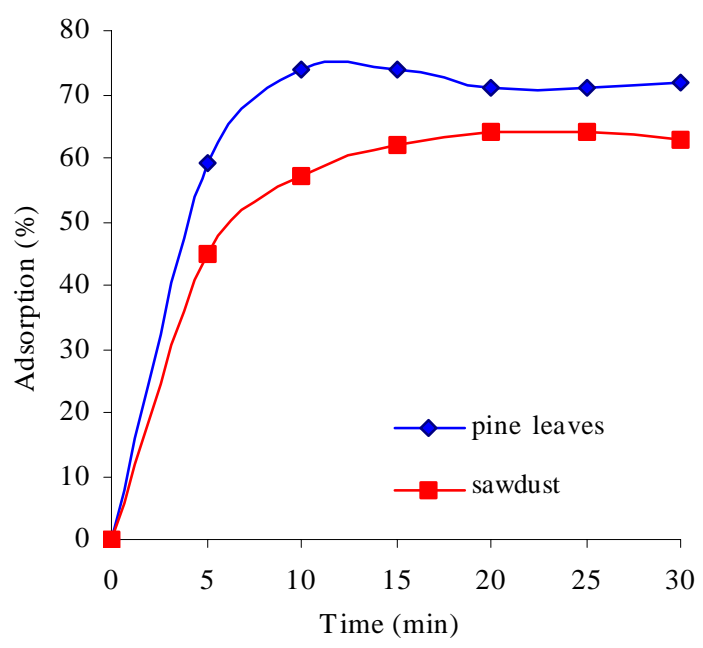

Fig. 1: Effect of contact time on the chromium adsorption

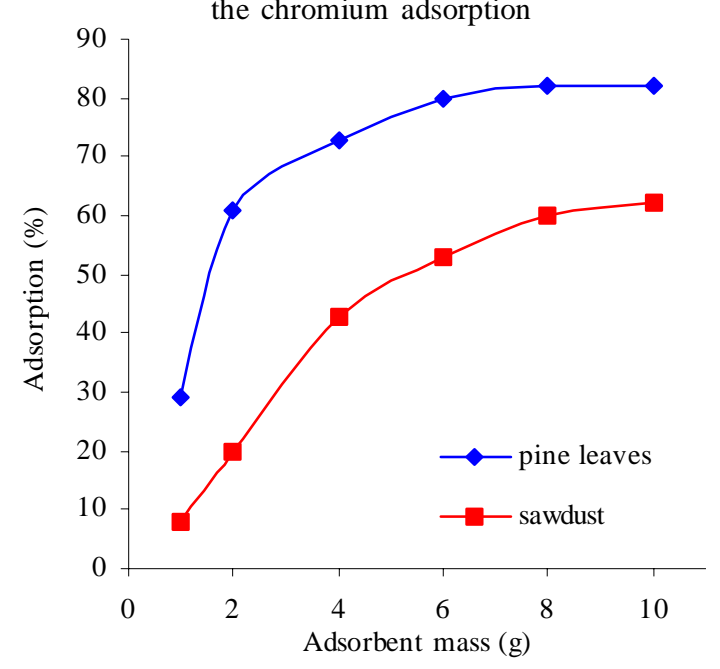

Fig. 2: Effect of adsorbent mass on the chromium adsorption capacity

\section{Effect of $p H$}

Chromium exhibits different types of $\mathrm{pH}$ dependent equilibria in aqueous solutions. As the $\mathrm{pH}$ is shifted, the equilibrium will also shift; in the $\mathrm{pH}$ range 2-6, $\mathrm{HCrO}_{4}^{-}$, and $\mathrm{Cr}_{2} \mathrm{O}_{7}^{2-}$, ions are in equilibrium. At lower $\mathrm{pH}(\mathrm{pH}<2.0)$ values, $\mathrm{Cr}_{3} \mathrm{O}_{10}$ - and $\mathrm{Cr}_{4} \mathrm{O}_{13}{ }^{2-}$ species are formed. The removal of $\mathrm{Cr}(\mathrm{VI})$ by sawdust and pine 
leaves at different pHs at an initial $\mathrm{Cr}(\mathrm{VI})$ concentration of $5 \mathrm{mg} / \mathrm{L}$, a temperature of $25^{\circ} \mathrm{C}$, particle size of 20-30 mesh was investigated. As illustrated in Fig. 3, The optimum initial $\mathrm{pH}$ was observed at $\mathrm{pH} 2.0$. This observation may be attributed to the fact that by decreasing $\mathrm{pH}$, hydroxyl groups in lignocellulosic wastes, tend to diffuse into the solution, so, it would be more probable for $\mathrm{Cr}_{2} \mathrm{O}_{7}^{2-}$ ions to be adsorbed on available adsorption sites. Using a Fourier transform infrared spectrometer (FTIR) analysis showed a wide pick at about $3400 \mathrm{~cm}^{-1}$ that confirm the existence of hydroxyl groups in either sawdust and pine leaves. As illustrated in Fig. 3, for pine leaves, 99\% of Cr(VI) was adsorbed from a solution of $5 \mathrm{mg} / \mathrm{L}$ at $\mathrm{pH} 2.0$, whereas a $15 \%$ reduction in biosorption was determined as the $\mathrm{pH}$ shifted from 2.0 to 6.0. In the case of sawdust, this decrease was about $22 \%$.

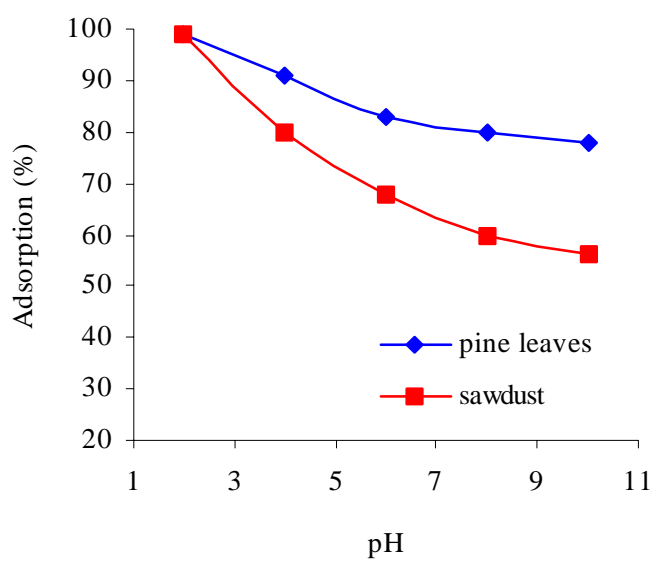

Fig. 3: Effect of $\mathrm{pH}$ on the chromium adsorption

\section{Effect of temperature}

The results obtained and presented in Fig. 4 indicate that an increase of the temperature in the range of 20$60^{\circ} \mathrm{C}$ had considerable effect on chromium adsorption by sawdust but had a restricted effect on chromium adsorption by pine leaves. As shown, at the temperature below $40^{\circ} \mathrm{C}$, pine leaves have higher chromium adsorption capacity. The necessary time to reach adsorption equilibrium for the different temperatures was practically the same $(15 \mathrm{~min})$. If adsorption is governed only by physical phenomena, an increase in temperature will result a decrease in adsorption capacity. Therefore, experimental results show that predominant mechanism is chemical adsorption.
Removal of hexavalent...

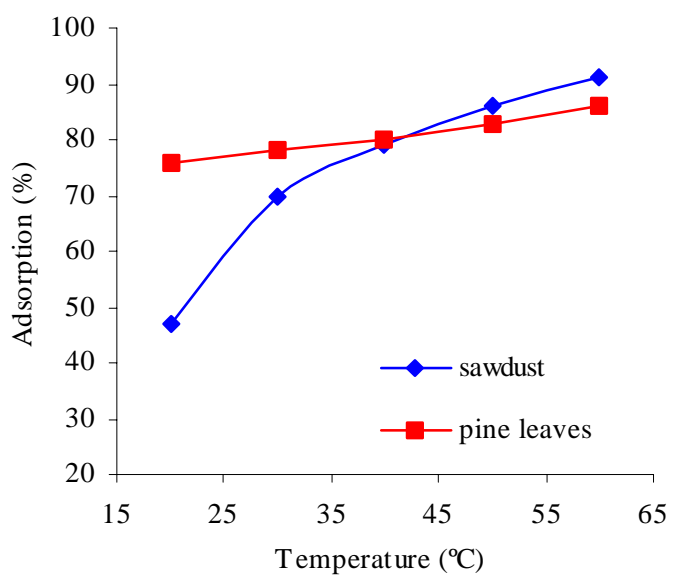

Fig. 4: Effect of temperature on the adsorption of chromium

Effect of initial chromium ion concentrations

As illustrated in Fig. 5, in the case of sawdust, by changing the initial concentration of $\mathrm{Cr}(\mathrm{VI})$ solution from 1 to $10 \mathrm{mg} / \mathrm{l}$, chromium removal reduced from $62 \%$ to $45 \%$ at $25^{\circ} \mathrm{C}$, pH5.0 and particle size of 20-30 mesh. But for pine leaves, initial concentration of $\mathrm{Cr}(\mathrm{VI})$ solution (in the range of 1-10 $\mathrm{mg} / \mathrm{l}$ ) had a restricted effect on chromium adsorption capacity. It was also noticed that amount of $\mathrm{Cr}$ ions on the solid phase with lower initial concentration of $\mathrm{Cr}(\mathrm{VI})$ was smaller than the amount when higher initial concentrations were used.

\section{Effect of particle size}

The batch adsorption experiments were carried out by using various particle sizes of the adsorbent (20-30 mesh and 30-50 mesh) at $\mathrm{pH} 5,25^{\circ} \mathrm{C}, 300 \mathrm{rpm}$ and initial concentration of $5 \mathrm{mg} / \mathrm{l}$.

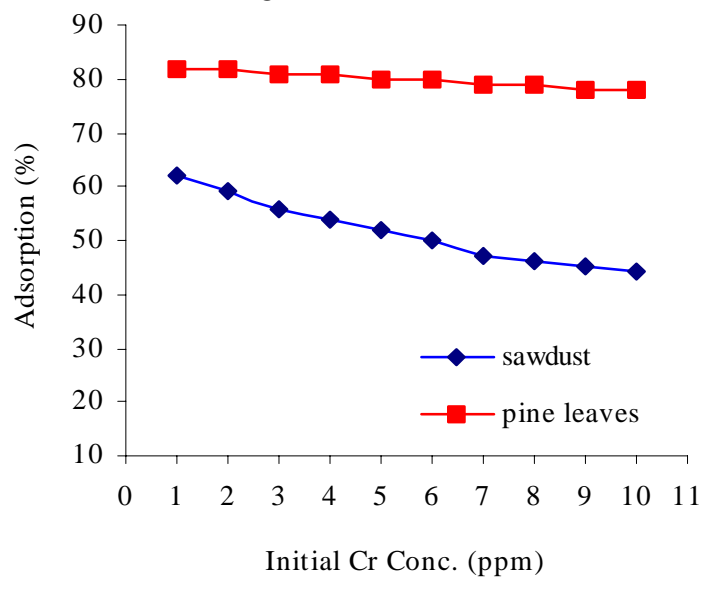

Fig. 5: Effect of initial chromium ion concentrations on the chromium adsorption 
The removal of $\mathrm{Cr}(\mathrm{VI})$ ions at different particle sizes showed that the capacity of chromium adsorption at the equilibrium increased with the decrease in particle sizes. The relatively higher adsorption with smaller adsorbent particle may be attributed to the fact that smaller particles yield large surface areas and indicating that chromium ion adsorption occurs through a surface mechanism. It was also noticed that, there is a tendency that a smaller particle produces shorter time to equilibration. Thus, for particle size of 20-30 mesh, the time required was about $15 \mathrm{~min}$, while for particle sizes of 30-50 mesh, the necessary time was about $10 \mathrm{~min}$. These observations suggest that the chromium adsorption kinetic is largely affected by the particle size. Results are shown in Fig. 6.

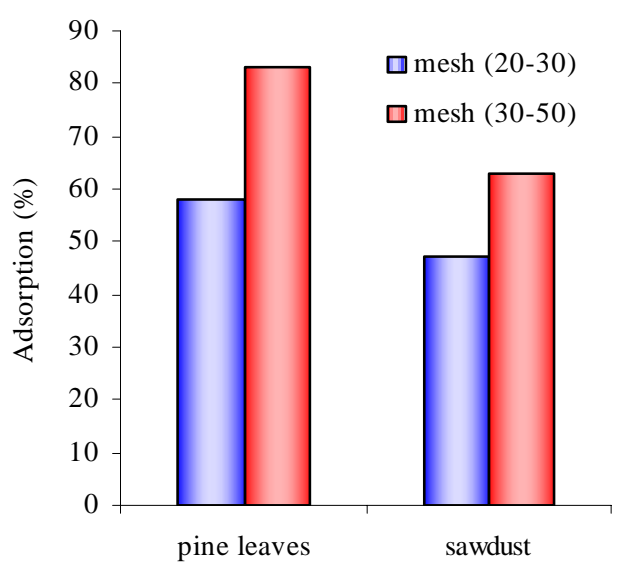

Fig. 6: Effect of particle size on the chromium adsorption

\section{Adsorption isotherms}

Two isotherms, as described below in Eqs. (1) and (2), were used for fitting the experimental data obtained at $25( \pm 2)^{\circ} \mathrm{C}$ and at $\mathrm{pH} 5.0$.

Langmuir equation:

$1 / q_{e}=1 /\left(\theta \cdot b . C_{e}\right)+1 / \theta$

Freundlich equation:

$\log \mathrm{q}_{\mathrm{e}}=\log \mathrm{K}+1 / \mathrm{n} \log \mathrm{C}_{\mathrm{e}}$

where:

$\mathrm{q}_{\mathrm{e}}$ is the amount adsorbed at equilibrium (mg/g)

$\mathrm{C}_{\mathrm{e}}$ is the equilibrium $\mathrm{Cr}(\mathrm{VI})$ concentration in solution (mg/L).

The other parameters are different isotherm constants, which can be determined by regression of the experimental data. Due to inconvenience of evaluating three isotherm parameters, the two-isothermparameter equations (Langmuir, Freundlich) are more widely used than the three-isotherm-parameter equation (Redlich-Peterson equation). Though, the three-isotherm- parameters equations mostly provide a better fit of the isotherm data than a two-isothermparameters one. The estimated model parameters with correlation coefficient $\left(\mathrm{R}^{2}\right)$ for the different models are shown in Tables 1 and 2.

Table 1: Estimated isotherm parameters for $\mathrm{Cr}$ (VI) adsorption by sawdust

\begin{tabular}{|c|c|c|c|}
\hline \multirow{3}{*}{$\begin{array}{l}\text { Langmuir equation } \\
1 /_{\mathrm{qe}}=1 / \theta \cdot \mathrm{b} \cdot \mathrm{c}_{\mathrm{e}}+1 / \theta\end{array}$} & \multicolumn{3}{|c|}{$\begin{array}{c}\text { Estimated isotherm } \\
\text { parameters at } 25^{\circ} \mathrm{C} \text { and } \\
\text { pH }=5.0\end{array}$} \\
\hline & $\mathrm{R}^{2}$ & $\theta$ & b (l/mg) \\
\hline & 0.975 & $\begin{array}{c}(\mathrm{mg} / \mathrm{g}) \\
0.198\end{array}$ & 0.219 \\
\hline Freundlich equation & $\mathrm{R}^{2}$ & $\mathrm{~K}$ & $\mathrm{n}$ \\
\hline $\log q_{e}=\log K+1 / n \log C_{e}$ & 0.993 & 0.229 & 1.298 \\
\hline
\end{tabular}

Table 2: Estimated isotherm parameters for $\mathrm{Cr}$ (VI) adsorption by pine leaves

\begin{tabular}{|c|c|c|c|}
\hline \multirow[b]{2}{*}{$\begin{array}{l}\text { Langmuir equation } \\
1 / /_{\mathrm{qe}}=1 / \theta \cdot \mathrm{b} \cdot \mathrm{c}_{\mathrm{e}}+1 / \theta\end{array}$} & \multicolumn{3}{|c|}{$\begin{array}{c}\text { Estimated isotherm } \\
\text { parameters at } 25^{\circ} \mathrm{C} \text { and } \\
\mathrm{pH}=5.0\end{array}$} \\
\hline & $\begin{array}{c}R^{2} \\
0.828\end{array}$ & $\begin{array}{c}\theta \\
(\mathrm{mg} / \mathrm{g}) \\
0.470\end{array}$ & $\begin{array}{c}\text { b (l/mg) } \\
0.708\end{array}$ \\
\hline Freundlich equation & $\mathrm{R}^{2}$ & K & $\mathrm{n}$ \\
\hline $\log q_{e}=\log K+1 / n \log C_{e}$ & 0.952 & 0.277 & 0.342 \\
\hline
\end{tabular}

\section{DISCUSSION AND CONCLUSION}

The present study showed that lignocellulosic solid wastes such as sawdust and pine leaves can be used as effective adsorbents for removal of $\mathrm{Cr}(\mathrm{VI})$ from wastewater. These natural wastes are available in large quantity and can be used as an alternative to existing commercial adsorbents for removal of $\mathrm{Cr}(\mathrm{VI})$. The removal of this carcinogenic toxicant was found to depend on materials, dosage, $\mathrm{pH}$, Temperature, initial concentration of $\mathrm{Cr}(\mathrm{VI})$ and time. The contact time for the maximum adsorption required is nearly 15 min and optimum $\mathrm{pH}$ for highest $\mathrm{Cr}(\mathrm{VI})$ sorption is 2.0. The equilibrium sorption data are satisfactorily fitted with Freundlich and Langmuir equations. The calculated values of the dimensionless separation factor from the Langmuir constant confirm favourable sorption of $\mathrm{Cr}(\mathrm{VI})$ onto sawdust and pine leaves. 


\section{ACKNOWLEDGMENT}

The Authors are thankful to Dr. Mohammad Ebadi, Head, Department of Chemical Engineering, Islamic Azad University, Birjand. The authors are also grateful to Dr. Alireza Harifi and Mr. Behrouz Baniasadi for their guidance and technical assistance.

\section{REFERENCES}

Cieslak-Golonka, M., (1996). Toxic and mutagenic effects of chromium (VI). Polyhedron, 15 (21), 3667-3918.

Dakiky, M., Khamis, M., Manassra, A. and Mereb, M., (2002). Selective adsorption of chromium (VI) in industrial wastewater using low-cost abundantly available adsorbents. Advances in Environmental Research, 6 (4), 533-540.

EPA, (1990). Environmental Pollution Control Alternatives. Environmental Protection Agency, EPA/625/5-90/025, EPA/625/489/023, Cincinnati, US

Espinola, A., Adamian, R. and Gomes, L. M. B., (1999). An innovative technology: natural coconut fibre as adsorptive medium in industrial wastewater cleanup. Proc. TMS Fall Extraction and Processing Conference, Vol. 3, p 2057-2066. Iqbal, M., Saeed, A. and Akhtar, N., (2002). Petiolar, feltsheath of palm: a new biosorbent for the removal of heavy metals from contaminated water. Bioresource Technology, January, 81 (2), 153-155.

Juang, R. S. and Shiau, R. C., (2000). Metal removal from aqueous solutions using chitosan-enhanced membrane filtration. Journal of Membrane Science, 165 (2), 159167.

Mahvi, A. H., Naghipour, D., Vaezi, F. and Nazmara, S., (2005). Teawaste as an adsorbent for heavy metal removal from industrial wastewaters. American Journal of Applied Sciences, 2 (1): 372-375.

Marshall, W. E. and Champange, E. T., (1995). Agricultural byproducts as adsorbents for metal ions in laboratory prepared solutions and in manufacturing wastewater. Journal of Environmental Science and Health - Part A Environmental Science and Engineering, 30 (2), 241-261.

Melo, M. and Disouza. S. F., (2004). Removal of chromium by mucilaginous seeds of Ocimum Basilicu. Bioresource Technology, 92 (2), 151-155.

Patterson J. W., (1985). Industrial Wastewater Treatment Technology. $2^{\text {nd }}$ Ed. Butterworth-Heinemann, London.

Saeed, A., Iqbal, M. and Akhtar, M. W., (2002). Application of biowaste materials for the sorption of heavy metals in contaminated aqueous medium. Pakistan Journal of Scientific and Industrial Research, 45 (3), 206-211.

Teixeria, T., Cesar, R., Zezzi, A. and Marco, A., (2004). Biosorption of heavy metals using ricemilling by-products. Characterisation and application for removal of metals from aqueous solutions. Chemosphere, 54 (7), 905-915.

Yan, G. and Viraraghavan, T., (2001). Heavy metal removal in a biosorption column by immobilized $\mathrm{M}$. rouxii biomass. Bioresource Technology, 78 (3), 243-249.

\section{AUTHOR(S) BIOSKETCHES}

Aliabadi, M., M.Sc., is a lecturer in the Department of Chemical Engineering, Islamic Azad University, Birjand Branch, Birjand. Email: majid.aliabadi@gmail.com

Morshedzadeh, K., B.Sc., Researcher in the Agriculture and Natural Resources Research Center of South Khorasan, Birjand. Email: kazem.morshedzadeh@gmail.com

Soheyli, H. R., B.Sc., Researcher in the Agriculture and Natural Resources Research Center of South Khorasan, Birjand. Email: hamidreza.soheyli@gmail.com

\section{This article should be referenced as follows:}

Aliabadi, M., Morshedzadeh, K., and Soheyli, H. R., (2006). Removal of hexavalent chromium from aqueous solution by Lignocellulosic solid wastes. Int. J. Environ. Sci. Tech., 3 (3), 321-325. 